has become almost impossible. Importation of plants from New Zealand has been attempted, but without marked success; and efforts have been made to establish seed-beds at Hermansburg Mission Station in Central Australia, where possibly infestation may not occur. Happily a means of overcoming the difficulty appears to have been demonstrated by $\mathrm{Dr}$. H. R. Angell, of the Council for Scientific and Industrial Research. His method is to allow benzol (or certain other hydrocarbon mixtures) to evaporate in the seed-beds during the night time and on dull days when the beds are under cover. While neighbouring untreated control beds may be completely destroyed, those subjected to the vapour remain healthy; in fact, no development follows even from artificial inoculation. During the present season extensive trials have been made in New South Wales, Victoria, South Australia and Western Australia with uniformly successful results. It is true that there remains a risk of infection when the seedlings are planted out, but this is relatively slight compared with the danger in the seed-beds; and it would appear that an economical, practical and effective means of destroying what is perhaps the greatest obstacle in the way of stabilising the tobacco industry in Australia has been developed and proved.

\section{Importance of Small Coal}

WHEN Dr. F. S. Sinnatt addressed the Institution of Civil Engineers on "Some Major Problems in the Utilisation of Coal" on March 17, he gave first place to the choice of coal suitable in composition, properties and preparation for the purpose in view, and emphasised the importance of collecting such information. Quoting examples from the work of the Coal Survey, he showed the great diversity of properties, even in one seam, and over comparatively small distances. Until these variations are exactly established, progress in rational marketing will be hampered. The needs of the consumer change. Large coal is in less demand, and is to an increasing extent being actually broken. The technique of mining, which has been designed to conserve lump coal, may be radically altered in favour of machine mining, which is prone to produce more fine coal. The breakage of coal is becoming of paramount importance to the coal industry, and involves many problems still requiring solution, and these are chemical, physical and particularly engineering. The disposal of fine coal dust involves consideration of the combustion of pulverised fuel, which steadily extends, hitherto mainly.in large units. For small units, coal can now be obtained ready pulverised, and the Fuel Research Station has developed a new burner with which it can be burnt with a short flame. The use of pulverised fuel in Lancashire boilers thus becomes practicable, with advantage to the performance. Apparently output of steam may be doubled without loss of efficiency. The development of firing with pulverised fuel in small units will call for means for retaining the emission of grit and sulphur, and although this has been solved so far as large power stations are concerned, there is still scope for plant suitable for smaller units.

\section{Atmospheric Pollution}

THE twenty-first report of the Investigation of Atmospheric Pollution issued by the Department of Scientific and Industrial Research (H.M. Stationery Office. 5s.) may be summarised in one sentence: "The general cleanness of our atmosphere is not improving" - a statement opposed to an impression widely held. The observations recorded in London seem particularly to point this way, and to show that while Metropolitan conditions get worse, provincial conditions improve. Some of the worst figures are recorded at London stations, compared with which the industrial areas in the provinces appear relatively good. This must be disquieting to residents of the Metropolis, and emphasises the need for more energy to promote the consumption of fuel by methods which minimise the emission of tar, soot and sulphur acids. Some of the anomalies suggest the need for caution in interpretation. After all, the figures relate only to the sites where examples are taken, and these are relatively few, and a statistical analysis by Mr. B. H. Wilsdon shows that other factors such as rainfall influence the results. The report deals with observations made for the year ending March 1, 1935, and it may be that increased industrial activity has involved an increased consumption of fuel which has compensated for some improvement in method of combustion.

\section{Cine-Radiography}

RöntGen announced his discovery of X-rays late in 1895. A few years afterwards, attempts were made to get cinematograph records of the pictures obtained by them; but they were crude. It was found that a speed from a $\frac{1}{2}$ to 1 second is perfectly effective for a good many movements. In a paper read to the Institution of Electrical Engineers on March 19, Mr. Russell J. Reynolds gave the latest developments in cine-radiography. There are two methods in general use. In the direct method, a band of film is placed in the position normally occupied by the fluorescent screen. This has the disadvantage that the dimensions of each exposure must be at least 4 in. $\times 5$ in. A film of this size is very costly, and an apparatus capable of moving it at the rate of 8 or more ex. posures per second is cumbersome and difficult to design. In the indirect method, the image on the fluorescent screen is photographed with an ordinary cinematograph apparatus. The chief difficulty in obtaining a sufficiently brilliant image on the screen lies in the fact that the film is minute and moves at a high speed. The heavy currents necessary wear out the tubes quickly, and it is dangerous to expose the patient to intense radiation for the time necessary to take the film. It has to be remembered also that the effect of the rays is cumulative. Mr. Reynolds gives full particulars of the apparatus he has evolved to overcome the difficulties of the indirect method. It gives a sufficiently brilliant screen picture to impress itself satisfactorily on the film when exposed for only a small fraction of a second. The film is protected from exposure to the rays, and the exposure of the patient to the rays is harmless. By this ap. paratus the radiologist obtains a rapid, inexpensive 
and permanent record of the functioning of the heart, lungs, thorax, etc. These records can easily be sent by post to the specialist in charge of the case.

\section{The Royal Cornwall Polytechnic Society}

THE annual report of the Royal Cornwall Polytechnic Society for 1935 provides ample evidence that although the Society has passed its centenary (see also p. 547 of this issue), age does not diminish its activities, and that it continues to play an import. ant part in stimulating interest in education and industry throughout the county. Foremost among its proceedings are its exhibition and summer meeting, held last year at Penzance. At the exhibition both art and science were well represented, while the industrial exhibits included a working model of the flotation process of separating minerals that contain an excess of sulphides. There was also a special section of scientific apparatus used for teaching. The report contains three original memoirs, one on the ancient mining districts of Cornwall by Mr. F. J. Stephens, another on Cornwall's part in ceramic history by Mr. E. A. Rees and a third on some minor foundries of Cornwall, based on material collected by the late Mr. S. Michell. It also includes the report of the Cornwall Rainfall Association for 1934 and the report on the Falmouth Observatory, with meteorological notes and tables for 1935. The observatory receives a grant from the Falmouth Town Council, and is inspected periodically on behalf of the Air Ministry. In a comparison of the records at Falmouth with those in other parts of England and Wales, Mr. W. T. Hooper, the superintendent of the observatory, says : "It will be seen therefore that the maximum temperature range at Falmouth was $52^{\circ}$, as compared with $79^{\circ}$ elsewhere, and our hottest day was $13^{\circ}$ cooler, and our coldest day $14^{\circ}$ warmer than the extreme temperature as a whole. This equability is the outstanding characteristic of our local climate." As regards sunshine, "in the year's aggregate, percentage and daily average, Falmouth is a good third in order of merit".

\section{Working to Music}

Is the factory of the Standard Motor Co., Ltd., of Coventry, the employees work to music. According to the British Motor Number published with The Times of March 17, those sections of the factory where the noise is not too great are fitted with loud-speakers all supplied from a radio-gramophone unit. At set times during the day, programmes are given. When a suitable wireless programme is available it is given. At other times gramophone records bought by the Company are played. In those parts of the factory where the work is of a monotonous nature the music is particularly helpful, engendering an atmosphere of cheerfulness. Dance tunes and simple rousing marches are the most popular. Among other privileges many of the workers are allowed to smoke. Morning coffee and afternoon tea are provided, workpeople being allowed half an hour of freedom to visit the buffet in groups. The factory is designed to produce a com. plete car every four minutes. The parts of the car are carried on an ever-moving conveyor-the chassis taking $2 \frac{1}{2}$ days to complete its circuit-the various processes such as body painting and the assembling of the car, which takes $2 \frac{1}{2}$ hours, being co-ordinated. The workers are proud that only very rarely has a customer calling for delivery had to wait for his car. Conveyors take the materials from worker to worker, each one of whom performs a single operation. On the test beds the 9 horse-power models are not run under their own power but driven electrically. As the energy consumed is at once recorded, a sufficient indication of their condition and the general tightness of their parts is obtained. The Standard Co. plans to produce three hundred cars a day, and when the present extensions are completed will have a floor space of more than a million square feet.

\section{An International Air Force}

A MEMORANDUM on the functions of an international air force has been issued by the governing committee of the New Commonwealth and by the Parliamentary Group of the British Section of the Society. Discussing the uses of an international air force, it is emphasised that the code of policing regulations to be drawn up must distinguish between acts of aggression and cases of default. Two distinct policing functions are involved-those of defence and of enforcement. The role of the international air foree is that of a reinforcing agency, aimed at bringing aggressive action to a standstill. It is precluded from assuming the offensive, but to be effective the intervention of an international air force must be made in the shortest possible space of time. The main objective would be to paralyse the military activities of the aggressor and compel him to desist from hostilities, and distinction between military objectives and civilian centres is unlikely to be practicable. An international air force might also conceivably be called upon to enforce the decisions or awards of an international court or tribunal, but its main object is deterrent and its functions are those of a police and not of a military force. Attention is also directed to the psychological factors involved.

\section{Empire Fibres Exhibition}

AN Empire Fibres Exhibition is open at the Exhibition Pavilion of the Imperial Institute, South Kensington, S.W.7, until April 9. The object of the exhibition is partly to interest the general public, and especially school-children visiting the Institute, in vegetable fibres of the Empire, in the various methods of preparation for the market and in the different products into which they are converted; partly to interest technical experts and business men in existing and potential uses for Empire fibres. A series of eight stands or 'bays' comprise the exhibition. Two central bays, facing each other, are devoted to flax and linen exhibits organised by the Linen Industry Research Association with its headquarters at Lambeg, Northern Ireland. Here there are a number of exhibits showing the cultivation and processing of flax and its conversion into linen; also the various lines of research carried out at the Lambeg Research Institute under the guidance of the director, Dr. W. H. Gibson, and at the Flax 